\title{
MORTALIDADE POR DIABETES MELLITUS NO BRASIL, EM SANTA CATARINA, NA REGIÃO CARBONÍFERA E EMCRICIÚMA, NO PERÍODO DE 1996 A 2013
}

\begin{abstract}
Abigail Lopes
Mestranda em Saúde Coletiva, Universidade do Extremo Sul Catarinense, nutri.abigail@gmail.com Sinara Ribeiro Moraes Mestranda em Saúde Coletiva, Universidade do Extremo Sul Catarinense, sinara.rm@hotmail.com Merieli Medeiros Ronsani Deolinda Mestranda em Saúde Coletiva, Universidade do Extremo Sul Catarinense, merieli_ronsani@hotmail.com Júlia Peruchi Sehnem Mestranda em Saúde Coletiva, Universidade do Extremo Sul Catarinense, Juliaps13@hotmail.com Carlos Eduardo Souza da Silva Mestrando em Saúde Coletiva, Universidade do Extremo Sul Catarinense, carlosesilva41@gmail.com

Luciane Bisognin Ceretta Doutora, Universidade do Extremo Sul Catarinense, luk@unesc.net Ingrid Schweigert Perry Doutora, Universidade do Extremo Sul Catarinense, atputp@gmail.com
\end{abstract}




\section{Priscyla Waleska Simóes}

Doutora, Universidade do Extremo Sul Catarinense, pri@unesc.net

\section{RESUMO}

O Diabetes Mellitus (DM) já é considerado uma epidemia, tornando-se um grande desafio para os sistemas de saúde, no âmbito global. Tratase de uma doença metabólica. Contudo, as suas etiologias ainda estão pouco elucidadas (CHEN; MAGLIANO; ZIMMET, 2012). O DM é reconhecido como um grupo de doenças metabólicas, caracterizado por altos níveis glicêmicos, comprometendo, assim, o metabolismo e provocando o aparecimento de muitas outras comorbidades. Também tem relação com prejuízo da função do hormônio insulina, responsável pela entrada da glicose na célula. A incidência global de DM tem sido crescente; em 30 anos, passou a ser 12 vezes maior, sendo o DM tipo 2 o mais frequente. Recentemente, uma revisão calculou uma estimativa de 381,8 milhóes de pessoas com diabetes em 219 países e territórios diferentes, no ano de 2013. Além disso, previu uma projeção de 591,9 milhões de casos para 2035 (LEON; MADDOX, 2015). No Brasil, o DM foi a causa de 5,3\% dos óbitos ocorridos em 2011. Já em 2014, ocorreram 4,9 milhóes de mortes em todo o mundo, por essa mesma causa (ISER et al., 2015). Esse trabalho avaliou a taxa de mortalidade por Diabetes Mellitus no Brasil, no estado de Santa Catarina, na Região Carbonífera e no município de Criciúma, durante o período de 1996 a 2013. Esta pesquisa é um estudo ecológico e descritivo, com dados secundários do Sistema de Informações sobre Mortalidade (SIM), acessados via Departamento de Informática do Sistema Único de Saúde (DATASUS). Foi calculada a média e o desvio padrão da taxa de mortalidade nas quatro regióes e feita a série temporal dessa mesma variável, utilizando o Excel, versão 2010, para elaboração de cálculos e gráficos. Foi calculada a taxa pela divisão do número de óbitos por diabetes, pela população no mesmo local e período, e multiplicou-se por 100.000. Os dados analisados mostraram que a média 
nacional de mortalidade por Diabetes Mellitus (23,2 óbitos/100.000 habitantes), no período de 1996 a 2013, foi a maior; em seguida, ficou a Região Carbonífera (21,4 óbitos/100.000 habitantes); na sequência o estado de Santa Catarina (20,7 óbitos/100.000 habitantes); e, por último, o município de Criciúma (18,9 óbitos/100.000 habitantes). Na análise da série temporal desse mesmo período, observou-se que o Brasil e Santa Catarina apresentaram uma taxa crescente, variando de 16,8 a 28,9 óbitos/100.000 habitantes e de 15,6 a 24,9 óbitos/100.000 habitantes, respectivamente. Entretanto, houve leve variação das taxas no decorrer do período. Por outro lado, outras duas regióes mostraram oscilação maior na taxa de mortalidade durante o período avaliado. A taxa de mortalidade por Diabetes, para a Região Carbonífera, variou de 17,5 a 27,9 óbitos/100.000 habitantes. Já no município de Criciúma, essa variação foi de 16,3 a 20,3 óbitos/100.000 habitantes. Apesar disso, as duas regiôes tiveram períodos de oscilação maior do que a máxima do intervalo de variação. A Região Carbonífera teve maior taxa de mortalidade no ano de 2009 (28,1 óbitos/100.000 habitantes). No município de Criciúma, esse pico ocorreu mais cedo, no ano de 1999 (28,0 óbitos/100.000 habitantes). Um estudo temporal que descreveu as taxas de mortalidade no Brasil e suas regióes de 2000 a 2011 encontrou declínio de 1,7\% nas taxas de mortalidade por DM, sendo este responsável por 5,3\% das mortes nesse período, com uma taxa de mortalidade que variou de 40,6 óbitos/100.000 habitantes para 33,7 óbitos/100.000 habitantes (MALTA et al., 2014). Outra pesquisa que considerou a mortalidade por complicaçóes agudas do DM, no período de 2006 a 2010, mostrou uma taxa de 2,45 óbitos/100.000 habitantes, compreendendo de 6,8\% a 22,9\% dos óbitos em que o DM foi causa base (KLAFKE et al., 2014). Um dos fatores apresentados em todos os estudos, em relação aos sistemas de informação, foi a questão do erro causado pela subnotificação dos óbitos, bem como de outras informaçóes. Em nosso estudo, a taxa de mortalidade, de forma geral, mostrou-se crescente em todas as regióes estudadas, sendo que a média nacional se sobrepôs às demais regióes. No entanto, a partir de 2000, houve uma pequena queda percentual dessas taxas. Por se tratar de um estudo ecológico, futuras pesquisas devem investigar as estatísticas apresentadas nesse trabalho. 
Palavras-chave: Diabetes Mellitus; Saúde Coletiva; Sistema de Informações sobre Mortalidade; Informática em Saúde; Epidemiologia.

\section{INSTITUIÇÃO FINANCIADORA}

Programa de Bolsas Universitárias de Santa Catarina - UNIEDU.

\section{REFERÊNCIAS}

CHEN, L.; MAGLIANO, D.; ZIMMET, P. Z. The worldwide epidemiology of type 2 diabetes mellitus-present and future perspectives. Nature Reviews Endocrinology [on-line], v.8, n.4, p.228-236, 2012.

ISER, B. P. M. et al. Self-reported diabetes prevalence in Brazil: results from national health survey 2013. Epidemiologia e Serviços de Saúde, Brasília, v.24, n.2, p.305-314, 2015.

KLAFKE, A. et al. Mortalidade por complicaçôes agudas do diabetes melito no Brasil, 2006-2010. Epidemiologia e Serviços de Saúde, Brasília, v.23, n.3, p.455-462, 2014.

LEON, B.; MADDOX, T. Diabetes and cardiovascular disease: epidemiology, biological mechanisms, treatment recommendations and future research. World Journal of Diabetes [on-line], v.6, n.13, p.1246, 2015.

MALTA, D. C. et al. Mortalidade por doenças crônicas não transmissíveis no Brasil e suas regióes, 2000 a 2011. Epidemiologia e Serviços de Saúde, Brasília, v.23, n.4, p.599-608, 2014. 